\title{
Perspectiva do papel da orientação profissional de jovens de municípios periféricos pr, brasil
}

\section{Perspective on the role of professional orientation of young people in peripheral municipalities pr, brazil}

Marcos Clair Bovo,

Fabiane Freire França, Solange A. Loch, Juliano Domingues da Silva

\section{Resumo:}

Esta pesquisa é derivada do projeto "UNESPAR/FECILCAM em diálogo com a Educação Básica: jovens ao encontro dos caminhos profissionais" desenvolvido em sete municípios da Mesorregião Centro Ocidental Paranaense. Diante da análise realizada, levanta-se a seguinte indagação: A orientação profissional pode contribuir para a pretensão profissional de jovens de municípios periféricos? Para responder a essa questão, propóe-se uma abordagem interdisciplinar que engloba os campos da Geografia, Pedagogia e Economia. Para isso, pauta-se nas teorias sobre orientação profissional e pequenas cidades (municípios periféricos). A natureza deste estudo é de pesquisa empírica e descritiva, com abordagem quantitativa e estratégia de pesquisa do tipo survey, realizada por meio de questionários aplicados in loco com 370 estudantes do $3^{\circ}$ ano do Ensino Médio, de escolas públicas de municípios da Mesorregiāo, Centro Ocidental Paranaense. Para análise dos dados, aplicou-se regressão múltipla linear. Como resultados, verifica-se que projetos de orientação profissional realizados em municípios periféricos colaboram para a pretensão dos jovens ingressarem em cursos superiores.

\begin{abstract}
:
This research is derived from the Project "UNESPAR/FECILCAM em diálogo com a Educação Básica: jovens ao encontro dos caminhos profissionais" (UNESPAR/FECILCAM in dialogue with basic education: the young meeting professional paths), developed in seven municipalities from Paranás Midwest Mesoregion. In face of the analysis performed, the following question is raised: Can professional guidance contribute to the young's professional aspiration in peripheral municipalities? To answer this question, an interdisciplinary approach is proposed, encompassing the fields of Geography, Pedagogy and Economy. Thus, the study is based on theories about professional guidance and small towns (peripheral municipalities). The study has an empirical and descriptive research nature, with a quantitative approach and survey research strategy, performed through questionnaires applied in loco with 370 high school students from the 3 rd grade in public schools from Paranás Midwest Mesoregion municipalities. For data analysis, it was applied multiple linear regression. The results have shown that professional guidance projects performed in peripheral municipalities contribute to the young's aspiration to enter higher education.
\end{abstract} *Universidade Estadual do Paraná- Campus de Campo Mourão. , PR, Brasil a Mr, Brasil

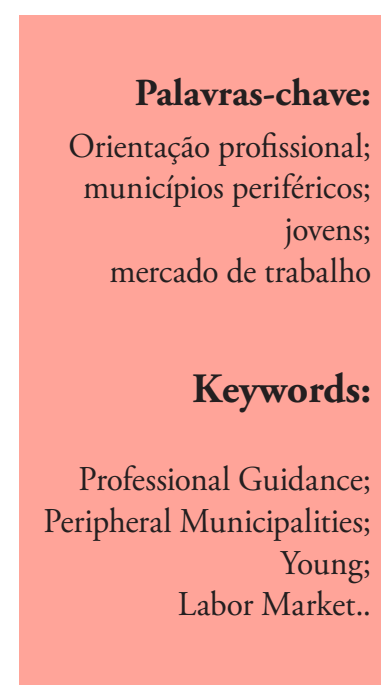




\section{Introduçáo}

A Orientação Profissional ganha importância como conhecimento científico em virtude dos múltiplos campos de atuaçáo que suas discussóes contemplam, como a evasão no Ensino Superior, indecisão dos jovens para escolher suas futuras profissóes, inúmeras fontes de influência no seu processo de decisão, etc. Diante desse cenário, levanta-se a seguinte indagação: a orientação profissional pode contribuir para a pretensão profissional de jovens de municípios periféricos? 1 Para responder a essa questão, propóe-se uma abordagem interdisciplinar que engloba os campos da Geografia, Pedagogia e Economia. Assim, com base nas teorias sobre orientação profissional e pequenas cidades (municípios periféricos), esta pesquisa tem como objetivo investigar a influência da orientação profissional para a pretensão dos jovens ingressarem no Ensino Superior, com enfoque naqueles que residem em municípios periféricos.

Para tanto, adota-se como procedimento metodológico o desenvolvimento de uma pesquisa empírica e descritiva, com abordagem quantitativa e estratégia de pesquisa do tipo survey, realizada por meio de questionários aplicados in loco com 370 estudantes do $3^{\circ}$ ano do Ensino Médio, de escolas públicas de alguns municípios da Mesorregião, Centro Ocidental Paranaense.

Os dados foram analisados por meio de regressão múltipla linear, além de utilizar análise de componentes principais para criar um indicador social único que represente as condiçóes econômicas e sociais dos municípios estudados, com o intuito de classificá-los como periféricos ou centrais, conforme discussão de Fresca (2013) e Costa e Rocha (2013).

\section{Orientaçáo profissional e municípios periféricos}

As pesquisas sobre orientação profissional são recorrentes de vários campos do conhecimento científico, principalmente da Psicologia, da Educação e da Sociologia que têm se preocupado em investigar as diferentes estratégias metodológicas para orientar os jovens quanto à escolha profissional. Dada à importância que antecede a escolha do trabalho, Lima (2007, p. 30) enfatiza que:

[...] a escolha da profissão é uma das grandes causadoras de angústia ao ser humano, por ser uma decisão muito importante em sua vida. Ela transcende à própria pessoa, refletindo-se na família e na sociedade, visto que só por meio de seu trabalho o homem é reconhecido socialmente.

1 São pequenos municípios que apresentam vulnerabilidade social e são classificados a partir de quatro critérios que estão imbricados e devem ser analisados em conjunto: esvaziamento populacional, subordinação territorial, dependência econômica e indicadores sociais críticos (COSTA e ROCHA, 2013).
Assim, compreende-se a magnitude da importância do trabalho para o homem em sociedade. Lima (2007, p. 30) destaca que "o que fica do homem é a sua produção e o que marca a evolução da humanidade é o que o homem deixa registrado, por meio de seu trabalho".

A orientação profissional ocupa um importante papel nesse contexto, porque "somente de posse de mais oportunidades de reflexão sobre si mesmo e de informaçóes sobre o mundo ocupacional é que o indivíduo poderá encontrar respostas para suas dúvidas em relação à escolha do curso/profissão" (LIMA, 2007, p. 37).

A Orientação Profissional abrange um processo amplo, atuando em questôes informativas sobre profissôes e mercado de trabalho e questôes intrapsíquicas sobre o autoconhecimento de suas características pessoais, familiares e sociais, promovendo o encontro das afinidades do jovem com aquilo que poderá vir a realizar em forma de um projeto de vida profissional (VASCONCELOS, 2004).

Além de informar sobre as novas possibilidades de cursos, a orientação profissional deve proporcionar ao jovem, o autoconhecimento, refletir sobre seus gostos, visão de mundo e sobre o que almeja para seu futuro, incluindo um projeto de vida pessoal que envolva o profissional (DÁTILO e LIMA, 2011). Desse modo, a Orientação Profissional contribui para a autoconscientização dos jovens e demonstra as possibilidades que os estudos podem levá-los, "estimulando a busca do conhecimento como atividade primordial para a construção de uma carreira profissional que proporcione satisfação e prazer no trabalho a ser realizado" (DÁTILO e LIMA, 2011, p. 83).

Embora muitas pesquisas sobre orientação profissional tenham sido realizadas no campo da psicologia ou da sociologia, com abordagens de questóes intrapsíquicas, a ampla maioria das pesquisas assume um modelo de desenvolvimento de carreira focado na preparação para o mercado de trabalho (TEIXEIRA, et al. 2007), porque a orientação profissional é imbricada com o contexto econômico.

Ferretti (1988) corrobora essa premissa quando elabora um esquema conceitual da escolha e seleção ocupacional, no qual o início do processo se dá a partir da estrutura social do indivíduo (estratificação social, valores e normas culturais, características demográficas, tipo de economia e tecnologia) e termina com a entrada do indíviduo no mercado de trabalho. Dessa forma, a discussão sobre orientaçáo profissional não pode ser 
desvinculada das questôes econômicas, uma vez que os indivíduos visam o trabalho.

As teorias econômicas de escolha profissional procuram explicar a distribuição da força de trabalho por diferentes ocupaçóes e quais fatores conduzem os indivíduos a procurarem algumas profissóes e a recusarem outras (FERRETTI, 1988).

No entanto, a orientação profissional discutida pelo viés da economia faz parte de um campo contestado. Ferretti (1988) destaca que a escolha profissional não pode ser explicada apenas pelo enfoque clássico da economia com ênfase no mecanismo de oferta e demanda do mercado de trabalho, pois os mercados não são perfeitos, e os indivíduos não dispóem de informações a respeito das ocupaçóes, além de não terem como arcar com o custo da preparação profissional.

É nesse contexto que órgãos públicos intervêm no mercado de trabalho, promovendo diversas açóes voltadas à orientação profissional de jovens marginalizados, integrando-as à Educação Básica ou desenvolvendo programas profissionalizantes.

Se de um lado, com a falta de informação a respeito das ocupaçóes e as limitaçóes financeiras fazem com que os indivíduos optem por profissōes que são mais tangíveis pelas próprias condiçôes econômicas, sociais e culturais que podem desencadear frustraçóes pessoais e profissionais que são ingredientes fecundos para a baixa produtividade e a alta rotatividade de empregos.

Por outro lado, com açóes voltadas para a orientação profissional, subsidiando informações e qualificando os jovens por meio das profissóes escolhidas, notadamente, garantem: a satisfação pessoal, o desenvolvimento profissional, a permanência no emprego e, consequentemente, a promoção do incremento econômico do país.

Além disso, argumenta-se que a discussão sobre orientação profissional, seja no campo científico ou na prática, tem pouca ou nenhuma atenção voltada às questôes inerentes ao espaço onde os jovens vivem. As políticas governamentais voltadas à preparação dos jovens para a vida profissional refletem as prioridades do governo numa escala macroeconômica (CASTIONE, 2013), ao invés de privilegiar demandas que reflitam o contexto local.

Assim, esta pesquisa está assentada na discussão sobre o papel da orientação profissional que contemple o desenvolvimento de pequenas cidades que estão à margem dos programas macroeconômicos, em particular, municípios com vulnerabilidade social, denominados muncípios periféricos.

A ideia de municípios periféricos está diretamen- te ligada à discussão de pequenas cidades, que é uma preocupação atual no âmbito científico da Geografia, conforme demonstrado por Endlich (2013). A discussão sobre pequenas cidades tem por base a concepção de formação social, que permite compreender as especificidades da realização de um modo de produção de um determinado lugar, compreendido pela estrutura técnico-produtiva expressa geograficamente por certa localização dos homens, de atividades e de coisas no espaço, conforme afirma Fresca (2013).

Para Fresca (2013), as pequenas cidades surgem a partir de processos de formaçáo social que se dáo num determinado espaço, a partir das relaçôes sociais e econômicas que ocorrem entre os diversos agentes. Dessa forma, compreende-se uma cidade como sendo pequena a partir do grau de centralidade, isto é, das relaçóes econômicas que um dado núcleo urbano estabelece em determinada área a partir da oferta de bens e serviços, com correspondente domínio territorial.

Fresca (2013) argumenta que esse processo ocorre de forma diferente em vários espaços. Portanto, os fatores que levam a surgir pequenas cidades em um lugar não se repetem em outro. Assim, os estudos da geografia urbana ou da economia estão mais preocupados com fenômenos que ocorrem em municípios centrais, ignorando a ideia de que esses fenômenos podem ser diferentes nos pequenos municípios, devido às suas especificidades e formação social.

Nesse sentido, Costa e Rocha (2013) argumentam que a noção de municípios periféricos está embasada na teoria de desenvolvimento geográfico desigual e no materialismo histórico dialético. A classificação das pequenas cidades como municípios periféricos foi apresentada por Costa e Rocha (2009), e considera os seguintes critérios: a) Esvaziamento Populacional; b) Subordinação Territorial; c) Dependência Econômica; e d) Indicadores Sociais Críticos. Esses fatores estão imbricados, ou seja, acontecem de forma simultânea.

De forma geral, essas características dos municípios periféricos estão ligadas à ação do modo de produção capitalista e interesses privados do espaço sobrepostos aos interesses da sociedade (ENDLICH, 2013). Portanto, jovens que residem nesses municípios periféricos podem ter dificuldades para pensar sobre suas perspectivas em relaçáo ao futuro profissional, entrando no mercado de trabalho em qualquer ocupação que lhes seja oferecida, não visando um curso superior. Essa situação faz surgir à desmotivação em jovens com sua atuação profissional, não contribuindo para seu crescimento e, consequentemente, aumentando o quadro de esvaziamento populacional, subordinação territorial, de- 
pendência econômica e indicadores sociais críticos dos municípios periféricos. Diante desse cenário, surgem as hipóteses a serem exploradas nesta pesquisa.

Em primeiro lugar, no âmbito da discussão sobre orientaçáo profissional, acredita-se que os jovens que possuem informaçôes sobre as demandas e perspectivas do ambiente do mercado de trabalho têm a possibilidade de escolher um curso superior. Tetuet al (2011) relataram uma pesquisa com dez estudantes de Ensino Médio e, dentre as conclusóes, notaram que os jovens apresentavam expectativas em relação ao conhecimento das diversas profissóes para realizar a escolha do curso superior mais adequado e prazeroso. Os autores evidenciaram que os alunos se sentiam mais seguros com suas escolhas quando dispunham das informaçóes sobre as profissões.

Silva (2010) realizou pesquisa com 32 alunos secundaristas e identificou que o curso superior não foi uma opção expressiva, em razão da dificuldade do Ingresso nas instituiçôes públicas e o desconhecimento de programas de acesso ao Ensino Superior, desestimulando os alunos a prestar processos seletivos. Nesse sentido, verifica-se que a posse de informaçóes sobre os aspectos de ingresso e funcionamento do mundo do trabalho direciona os alunos a escolher o curso superior. Assim, propóe-se a seguinte hipótese:

H1: O conhecimento do mercado de trabalho dos jovens tem relação positiva e significativa com a pretensão em ingressar no Ensino Superior.

Em segundo lugar, espera-se que projetos de orientação profissional possam contribuir para que os jovens adquiram ou consolidem seus conhecimentos sobre o mercado de trabalho. A esse respeito, Dátilo (2011) relata o desenvolvimento de um projeto de orientaçáo vocacional, em que foi identificada a dificuldade dos jovens vestibulandos de escolher, com segurança e conhecimento, uma profissão diante das inúmeras possibilidades oferecidas pelo mercado de trabalho. O projeto do autor buscava contribuir para a tomada de decisão da escolha profissional tendo em vista o conhecimento e compreensão crítica diante das inúmeras variáveis que influenciam o processo, como informações profissionais, interesses e mercado de trabalho. Dátilo (2011, p. 83) conclui que o profissional da educação pode contribuir "com a conscientização dos jovens para alcançar novos objetivos de vida, estimulando a busca do conhecimento como atividade primordial para a construção de uma carreira profissional que proporcione satisfação e prazer no trabalho a ser realizado".

Lassance e Sparta (2003) destacam que uma das práticas da Orientação Profissional está relacionada ao papel do orientador profissional, que deve conhecer as mudanças atuais no mundo do trabalho, para orientar os jovens para as incertezas e instabilidades que dele advêm. Assim, dada essa competência disseminada pelos profissionais de orientaçáo profissional, acredita-se que a pretensão dos jovens de entrar no Ensino Superior pode ser influenciada pela combinaçáo dos conhecimentos que os mesmos possuem e os projetos de orientação de que participam. Assim, argumenta-se que:

$\mathrm{H} 2$ : O projeto de orientação profissional amplifica a relaçáo positiva entre conhecimento do mercado de trabalho dos jovens e a pretensão em ingressar no Ensino Superior.

Por fim, esta pesquisa centra-se no campo do conhecimento da Geografia, oriundo da discussão de pequenas cidades. Acredita-se que em municípios periféricos que apresentem vulnerabilidades e indicadores sociais críticos, como indicadores de desenvolvimento humano, os projetos de orientaçáo profissional apresentam mais efetividade, ou seja, os jovens que residem em municípios periféricos serão mais suscetíveis para pretender ingressar no Ensino Superior ao participarem de projetos de orientação profissional. Espera-se que, em municípios com menor vulnerabilidade, os jovens já disponham de mais informaçóes e alternativas para apoiar suas decisões, enquanto que em municípios periféricos isso não acontece pelo fato do Ensino Superior não ser a realidade do cotidiano.

Ribeiro (2003) realizou pesquisa com 252 jovens do Ensino Médio de escolas públicas da periferia da zona leste de São Paulo e identificou que, dentre os principais pontos levantados, há entre os alunos um sentimento de desinformação total sobre o mercado de trabalho, falta de material que possa esclarecer sobre as oportunidades de inserçáo no mercado de trabalho, necessidade de um trabalho de orientação profissional que fosse realizado na própria escola, e necessidade de espaços de reflexão sobre o futuro e o que fazer já no presente.

Apesar da pesquisa de Ribeiro (2003) não ter sido realizada em municípios periféricos, acredita-se que o local de estudo do autor se assemelha aos municípios com indicadores sociais críticos. Assim, dada a carência de informações nesses locais, a realização de projetos de orientação profissional terá mais sucesso no processo de decisão de escolha dos alunos do que em municípios que já dispóem dessas informaçóes. Portanto, argumenta-se que:

H3: O papel amplificador do projeto de orientação profissional na relação entre conhecimento do mercado de trabalho dos jovens e a pretensão em ingressar no Ensino Superior será maior nos municípios em que os indicadores sociais são críticos. 


\section{Procedimentos metodológicos}

Amostra. Para se testar as hipóteses da pesquisa, escolheu-se como população-alvo 370 alunos do $3^{\circ}$ ano do Ensino Médio de escolas públicas de sete municípios da Mesorregiáo Centro-Ocidental Paranaense (figura 1). $\mathrm{O}$ instrumento de coleta de dados utilizado foi o questionário estruturado. Num primeiro momento, aproximadamente 400 alunos participaram do projeto "UNESPAR/FECILCAM em diálogo com a Educação Básica: jovens ao encontro dos caminhos profissionais" que contou com sete encontros para promover a discussão sobre orientação profissional; autoconhecimento dos jovens; mecanismos e políticas de ingresso no Ensino Superior; e demandas do mercado de trabalho.

No final do projeto, os alunos foram abordados in loco e, após receberem a explicação dos objetivos da pesquisa, foram convidados a participar dela. Foram distribuídos 392 questionários estruturados. Deste total, 370 responderam todos os itens da pesquisa, sendo considerados válidos, representando uma taxa de respostas de $94 \%$. A técnica de amostragem utilizada foi a não probabilística por conveniência.

Procedimentos. Para mensurar os construtos, foram criados itens do tipo intervalar. Essa técnica de escalonamento exigiu que os alunos indicassem o grau de concordância com os itens segundo uma escala de 5 pontos. Ao todo, o questionário foi composto por 08 itens divididos em 2 construtos. Sendo assim, o número amostral é compatível com a quantidade de itens do questionário, satisfazendo a condição para a análise multivariada de ao menos 10 respondentes para cada item (MARÔCO, 2010). Foram avaliadas as medidas de assimetria e curtose, utilizando como referência valores inferiores a 3 para assimetria e inferiores a 7 para curtose, permitindo pressupor a normalidade dos dados (MARÔCO, 2010). Já para os valores extremos, foram diagnosticados os outliers multivariados segundo a medida de Distância de Mahalanobis (MARÔCO, 2010). Como não foi verificada a presença de outliers, a amostra final contou com 370 respondentes.

Análises dos Dados. Quanto à análise dos dados, a relação direta foi testada regredindo a variável inde- pendente 'conhecimento do mercado de trabalho' sobre a variável dependente 'pretensão de ingressar no curso superior'. Já as relaçóes moderadas também foram testadas por meio da análise de regressão. Para tanto, foi adotado o modelo proposto por Baron e Kenny (1986). Para realizar a regressão, foi calculada a variável interativa, produto entre a variável independente (VI) e a variável moderadora (Mod), a qual foi acrescida ao modelo de regressão da variável dependente (VD). $\mathrm{O}$ modelo de regressão genérico está representado na equação 1 .

$$
\begin{aligned}
& \text { (1) } \\
& V D=\beta_{0}+\beta_{1} V I+\beta_{\mathbf{2}} \operatorname{Mod}+\beta_{\mathbf{3}} \text { VIxMod }+e \\
& V D=\beta_{0}+\beta_{1} V I+\beta_{\mathbf{2}} \operatorname{Mod}+\beta_{\mathbf{3}} \text { VIxMod }+e
\end{aligned}
$$

Nesse sentido, um modelo foi criado para testar o efeito moderador do projeto de orientaçáo profissional (POP) sobre a relação entre a variável independente 'conhecimento do mercado de trabalho' (CMT) sobre a variável dependente 'pretensão de ingressar no curso superior' (PCS). O modelo está descrito na equaçáo 2. Do mesmo modo, outro modelo foi criado para testar a moderaçáo de interaçáo tripla, no qual foi verificado o efeito moderador do 'indicador social' (IS) sobre a variável moderadora 'projeto de orientaçáo profissional' (POP) sobre a relação entre a variável independente 'conhecimento do mercado de trabalho' (CMT) sobre a variável dependente 'pretensáo de ingressar no curso superior' (PCS). O modelo está descrito na equação 3.

Para criar o Indicador Social, foi utilizada a Análise de Componentes Principais proposta por Kubrusly (2001), na qual os diversos indicadores dos municípios, mensurados por institutos oficiais de pesquisa, constantes na Tabela 1, foram combinados para formar um indicador único, no qual os baixos índices representam os municípios periféricos (valores negativos) com indicadores sociais críticos, e os altos índices representam os municípios centrais (valores positivos).

Mensuraçáo. Para mensurar o 'conhecimento do mercado de trabalho', foram utilizados três itens: "Antes de sua participação neste projeto, você já tinha ouvido

$$
\begin{aligned}
& \text { (3) } \quad P C S=\beta_{0}+\beta_{\mathbf{1}} P O P+\beta_{\mathbf{2}} C M T+\beta_{\mathbf{3}} I S+\beta_{\mathbf{4}} P O P x C M T+\beta_{\mathbf{5}} P O P x I S+\beta_{\mathbf{6}} C M T x I S+\beta_{7} P O P x C M T x I S \\
& P C S=\beta_{\mathbf{0}}+\beta_{\mathbf{1}} P O P+\beta_{\mathbf{2}} C M T+\beta_{\mathbf{3}} I S+\beta_{\mathbf{4}} P O P x C M T+\beta_{\mathbf{5}} P O P x I S+\beta_{\mathbf{6}} C M T x I S+\beta_{7} P O P x C M T x I S
\end{aligned}
$$


Tabela 1 - Indicadores utilizados na formação do Indicador Social

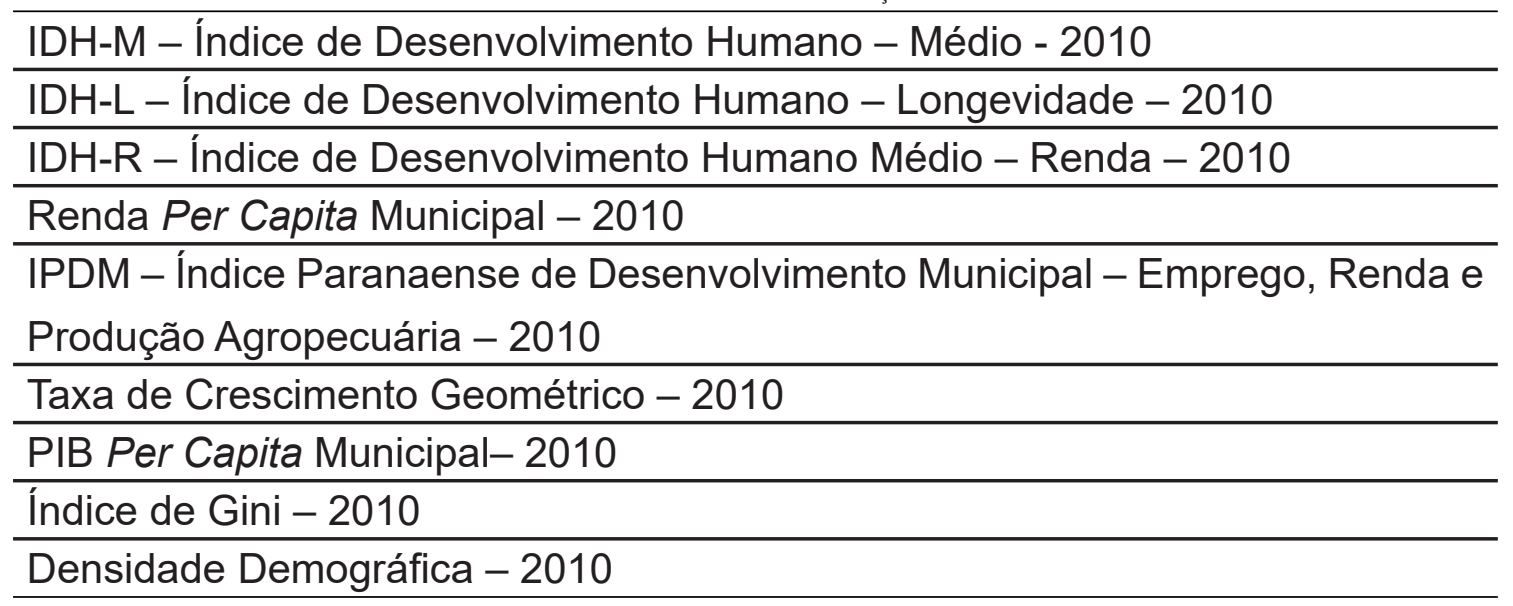

Fonte: Censo Demográfico IBGE (2010); IPARDES (2013).

falar sobre 'Orientação Profissional?”, "Antes de sua participação neste projeto, você já tinha ouvido falar sobre o mercado de trabalho?" e "Você conhece as profissóes que o mercado de trabalho brasileiro necessita atualmente?". Para mensurar o construto 'projeto de orientação profissional', foram utilizados cinco itens: "Você compreendeu os temas trabalhados no projeto (Orientação Profissional, Mercado de Trabalho)?", "Com a sua participaçáo no projeto, você buscou mais informaçôes sobre o mercado de trabalho, visando seu futuro profissional?", "O projeto contribuiu para seu futuro profissional?", "Participei das discussóes com questionamentos e contribuiçōes" e "Durante o projeto, minhas dúvidas foram esclarecidas". Finalmente, para mensurar a variável 'pretensão de ingressar no curso superior', foi utilizado o item: "Qual sua pretensão para o próximo ano?".

Posteriormente, foi determinada a validade fatorial das escalas, a qual afere a especificação correta dos itens de um determinado construto (MARÔCO, 2010). Na primeira solução, todos os itens apresentaram carga fatorial significativa e nas dimensôes esperadas. Dessa forma, na solução fatorial, os itens se agruparam conforme o esperado, em seus respectivos construtos. Todos os itens apresentaram cargas fatoriais significativas, superiores a 0,70 (HAIR et al., 2009). Os itens de cada construto também foram submetidos ao teste de confiabilidade de alfa de Cronbach. Todos os construtos tiveram medidas superiores a 0,70 , indicando um grau significativo de consistência interna dos seus itens (HAIR et al., 2009).

Para os testes de regressão, foram realizados testes de existência de multicolinearidade (VIF), a fim de não comprometer os resultados das análises. Todos os valores encontrados satisfizeram a condição proposta por Marôco (2010). Por fim, para melhor interpretação do efeito moderador, as relaçôes foram representadas graficamente, explorando a posiçáo da variável independente nas condiçốes de baixo e alto nível da variável moderadora (WEST et al., 1996).

\section{Análise dos resultados}

A amostra é composta por 370 jovens estudantes do $3^{\circ}$ ano do Ensino Médio dos turnos matutino, vespertino e noturno de escolas públicas de sete municípios da Mesorregião, Centro Ocidental Paranaense, conforme representado na Figura 1. Para obter uma heterogeneidade nas respostas, foram escolhidos municípios que apresentam baixos e médios IDH-M (Índices de Desenvolvimento Humano Médio) (IPARDES, 2013), conforme segue: Campo Mourão, IDH-M 0,757, foram entrevistados 50 jovens; Peabiru, IDH-M 0,723, foram entrevistados 27 jovens; Farol, IDH-M 0,715, foram entrevistados 34 jovens; Juranda, IDH-M 0,708, foram entrevistados 56 jovens; Araruna, IDH-M 0,704, foram entrevistados 98 jovens; Barbosa Ferraz, IDH-M 0,696, foram entrevistados 54 jovens; e Luiziana, IDH-M 0,668, foram entrevistados 51 jovens.

A Tabela 2 mostra a Correlação Linear de Pearson, na qual é realizada uma análise bivariada entre as variáveis do estudo. Pelos resultados obtidos, ao nível de significância de $\mathrm{p}<0,05$, pode-se afirmar que há correlação positiva e significante entre 'Conhecimento do Mercado de Trabalho' e 'Pretensão de ingressar no Ensino Superior', conforme direçâo da hipótese H1, demonstrando que as informaçôes sobre mercado de trabalho contribuem para a tomada de decisão dos jovens. 


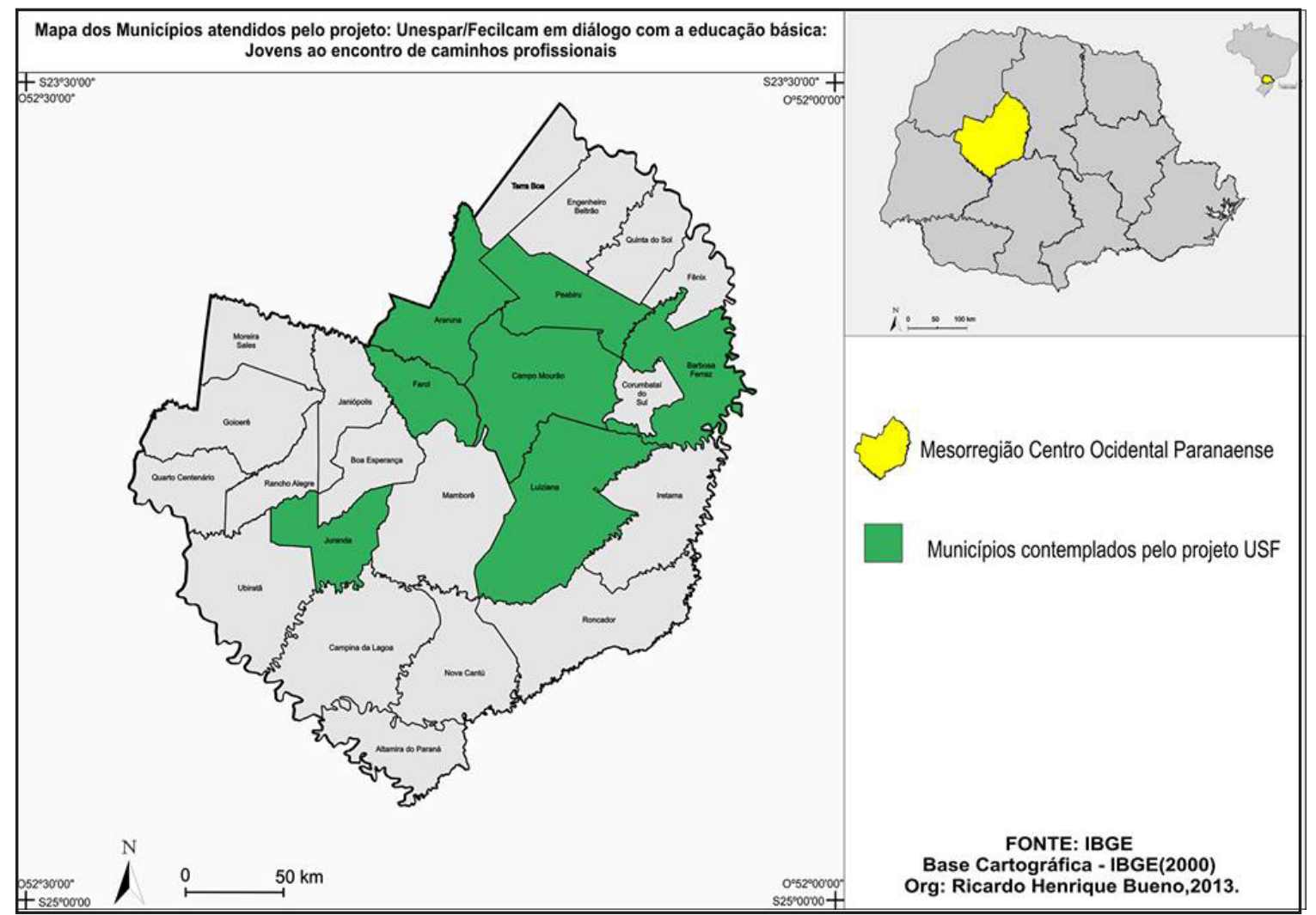

Figura 1 - Municípios pesquisados da Mesorregião Centro Ocidental Paranaense.

Fonte: Organizado pelos autores.

Dentre as variáveis de controle, pode-se verificar que há correlações significativas e negativas entre 'município' e 'pretensão de ingressar no Ensino Superior', e 'turno escolar' e 'conhecimento do mercado de trabalho', e também nota-se correlação significativa e positiva entre 'município' e 'indicador social'.

Para testar as hipóteses deste estudo, foram realizadas regressóes lineares das variáveis independentes e dependentes. Conforme verifica-se na Tabela 2, o primeiro modelo testa a regressão linear direta entre 'Conhecimento do Mercado de Trabalho' e 'Pretensão em ingressar no Ensino Superior'. Conforme esperado na hipótese $\mathrm{H} 1$, e já constatado na análise bivariada, o conhecimento sobre o mercado de trabalho contribui para os jovens tomarem a decisão de participar de processos seletivos para ingressar no Ensino Superior $(\beta=$ 0,232; $\mathrm{p}<0,05)$; assim, a hipótese H1 foi suportada. No segundo modelo, foram inseridas as variáveis de controle. No primeiro modelo, houve um poder de explicação de $19,92 \%$, enquanto no segundo modelo houve um poder explicativo de $20,94 \%$. A diferença no poder explicativo entre os dois modelos é de $\Delta \mathrm{R}^{2}=1,04$, mas não significativa.

Para testar as hipóteses interativas, adotou-se o modelo proposto por Baron e Kenny (1986). O procedimento foi estimar a variável interativa, produto entre a variável independente e a variável moderadora, a qual foi acrescida ao modelo de regressão da variável dependente. A tabela 3 apresenta os coeficientes náo padronizados e a significância resultantes dos dois modelos testados. A hipótese $\mathrm{H} 2$ mensura se a pretensão dos jovens de ingressar no Ensino Superior pode ser influenciada por projetos de orientaçáo profissional. Pode-se verificar que, quando o jovem possui informação sobre o mercado de trabalho e participa de projeto de Ensino Superior, sua escolha em fazer Ensino Superior é fortalecida $(\beta=0,165 ; \mathrm{p}<0,05)$; dessa forma, a hipótese $\mathrm{H} 2$ foi corroborada.O Gráfico 1 demonstra o efeito do papel moderador do projeto de orientação profissional na relaçáo entre conhecimento do mercado de trabalho e pretensão de ingressar no Ensino Superior. Pode-se verificar que o melhor resultado para a pretensão de ingressar no Ensino Superior foi obtido quando os jovens relataram que possuíam um alto nível de conhecimento do mercado de trabalho e obtiveram alto aproveitamento do projeto de orientaçáo profissional. Em contraste, quando os jovens relataram que não tinham informaçóes sobre $o$ mercado de trabalho e náo tiveram aproveitamento do 
Tabela 2 - Média, Desvio padrão e coeficientes de correlaçáo.

\begin{tabular}{|c|c|c|c|c|c|c|c|c|c|c|}
\hline \multicolumn{2}{|c|}{ Variável } & $\begin{array}{l}\text { M é - } \\
\text { dia }\end{array}$ & $\begin{array}{l}\text { De s v. } \\
\text { Pad. }\end{array}$ & Alfa & 1 & 2 & 3 & 4 & 5 & 6 \\
\hline 1 & $\begin{array}{l}\text { Conheci- } \\
\text { mento do } \\
\text { Mercado } \\
\text { de Traba- } \\
\text { lho }\end{array}$ & 3,07 & 0,74 & 0,73 & 1,00 & & & & & \\
\hline 2 & $\begin{array}{l}\text { Projeto } \\
\text { Orienta- } \\
\text { çáo Pro- } \\
\text { fissional }\end{array}$ & 4,21 & 0,92 & 0,81 & 0,58 & 1,00 & & & & \\
\hline 3 & $\begin{array}{l}\text { Indicador } \\
\text { Social }\end{array}$ & $-0,16$ & 0,91 & - & 0,31 & $-0,01$ & 1,00 & & & \\
\hline 4 & $\begin{array}{l}\text { Pretensão } \\
\text { E n s i n o } \\
\text { Superior }\end{array}$ & 3,48 & 1,49 & 0,69 & $0,26^{*}$ & 0,32 & $-0,09$ & 1,00 & & \\
\hline 5 & $\begin{array}{l}\text { Municí- } \\
\text { pio }\end{array}$ & - & - & - & $-0,07$ & 0,56 & $0,43^{* *}$ & $-12^{* *}$ & 1,00 & \\
\hline 6 & $\begin{array}{l}\text { Turno } \\
\text { escolar }\end{array}$ & - & - & - & $-0,10^{*}$ & $-0,00$ & $-0,08$ & 0,26 & 0,00 & 1,00 \\
\hline
\end{tabular}

Fonte: pesquisa realizada pelos autores em 2013

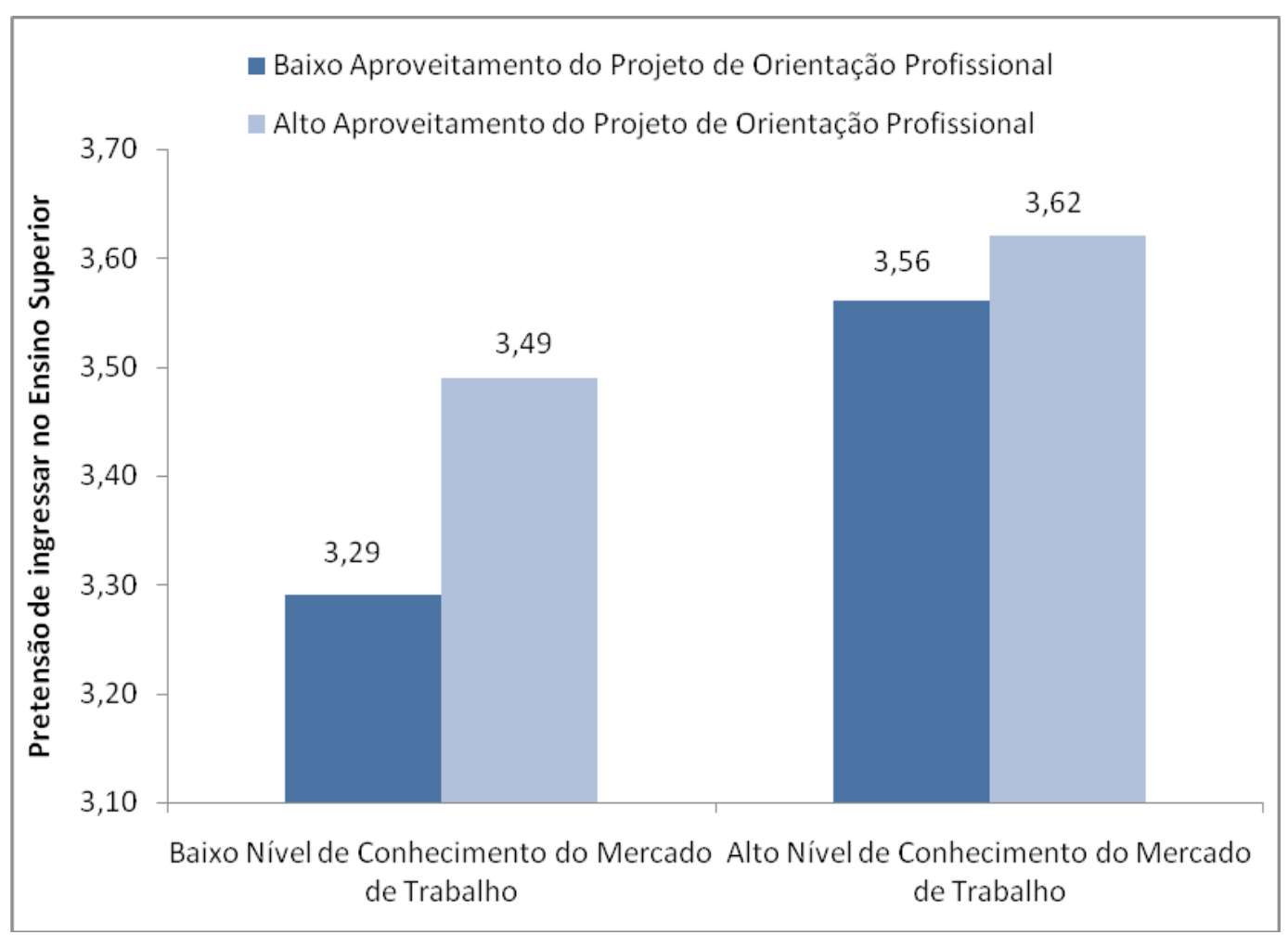

Gráfico 1 - Efeito moderador do Projeto de Orientação Profissional

Fonte: Pesquisa de campo realizada pelos autores em 2013 
Tabela 3- Análise de regressão dos efeitos diretos e interativos

\begin{tabular}{|c|c|c|c|c|c|c|}
\hline \multirow[b]{2}{*}{ Variáveis Independentes } & \multicolumn{2}{|c|}{$\begin{array}{l}\text { Pretensão } \\
\text { Curso Superior }\end{array}$} & \multicolumn{2}{|c|}{$\begin{array}{l}\text { Pretensão } \\
\text { Curso Superior }\end{array}$} & \multicolumn{2}{|c|}{$\begin{array}{l}\text { Pretensão } \\
\text { Curso Superior }\end{array}$} \\
\hline & Beta $(\beta)$ & Signif. & $\begin{array}{l}\mathbf{B} \text { e } \mathbf{t} \mathbf{a} \\
(\beta)\end{array}$ & Signif. & $\begin{array}{l}\text { B e t a } \\
(\beta)\end{array}$ & Signif. \\
\hline \multicolumn{7}{|l|}{ Efeito Direto } \\
\hline Conhecimento do Mercado de Trabalho & 0,232 & $0,053^{*}$ & 0,118 & $0,062 \dagger$ & & \\
\hline \multicolumn{7}{|l|}{ Variáveis de Controle } \\
\hline Turno Escolar & & & 0,042 & 0,115 & & \\
\hline Município & & & 0,012 & 0,194 & & \\
\hline \multicolumn{7}{|l|}{ Interação Dupla } \\
\hline $\begin{array}{l}\text { Conhecimento do Mercado de Trabalho } \\
\text { x Projeto Orientaçáo Profissional }\end{array}$ & & & & & 0,165 & $0,024^{*}$ \\
\hline \multicolumn{7}{|l|}{ Interação Tripla } \\
\hline $\begin{array}{l}\text { Conhecimento do Mercado de Trabalho } \\
\text { x Projeto Orientaçáo Profissional x Indi- } \\
\text { cador Social }\end{array}$ & & & & & $-0,067$ & $0,068 \dagger$ \\
\hline $\mathrm{R}^{2}$ & \multicolumn{2}{|l|}{$19,92 \%$} & \multicolumn{2}{|l|}{$20,94 \%$} & & \\
\hline
\end{tabular}

Fonte: Pesquisa de campo realizada pelos autores em 2013.

projeto de orientação profissional, sua pretensão de ingressar no Ensino Superior foi menor.

A hipótese $\mathrm{H} 3$ de tripla interação mensura se os jovens que residem em municípios periféricos serão mais suscetíveis para pretender ingressar no Ensino Superior se possuírem informaçóes do mercado de trabalho e participarem de projetos de orientação profissional do que jovens de municípios centrais.

Pode-se verificar, na tabela 2 , embora não significativa a um p de valor menor que 0,05 , que, quando o jovem possui informação sobre o mercado de trabalho, participa de projeto de Ensino Superior e reside em municípios periféricos, sua escolha em fazer Ensino Superior é fortalecida ( $\beta=-0,067 ; \mathrm{p}<0,06)$; dessa forma, a hipótese $\mathrm{H} 3$ foi corroborada parcialmente. $\mathrm{O}$ fato do $\beta$ apresentar valor negativo significa que a regressáo tem valor quase significativo para municípios periféricos, pois, como foi apresentado anteriormente, o indicador social representa um contínuo, no qual os valores negativos representam municípios com indicadores sociais críticos e valores positivos representam municípios centrais, com indicadores sociais melhores.

Os gráficos 2 e 3 demonstram a interação tripla do papel moderador do indicador social do município no efeito de moderação do projeto de orientação profissional quanto à relação entre conhecimento do mercado de trabalho e pretensão de ingressar no Ensino Superior. Pode-se verificar que o melhor resultado para a pretensão do Ensino Superior deu-se quando os jovens relataram que possuíam um alto nível de conhecimento do mercado de trabalho e obtiveram alto aproveitamento do projeto de orientação profissional em municípios periféricos, ou seja, com indicador social baixo.

Em contraste, nos municípios com baixo indicador social, quando os jovens relataram que não tinham informaçóes sobre o mercado de trabalho e não tiveram 


\section{Indicador Social Baixo}

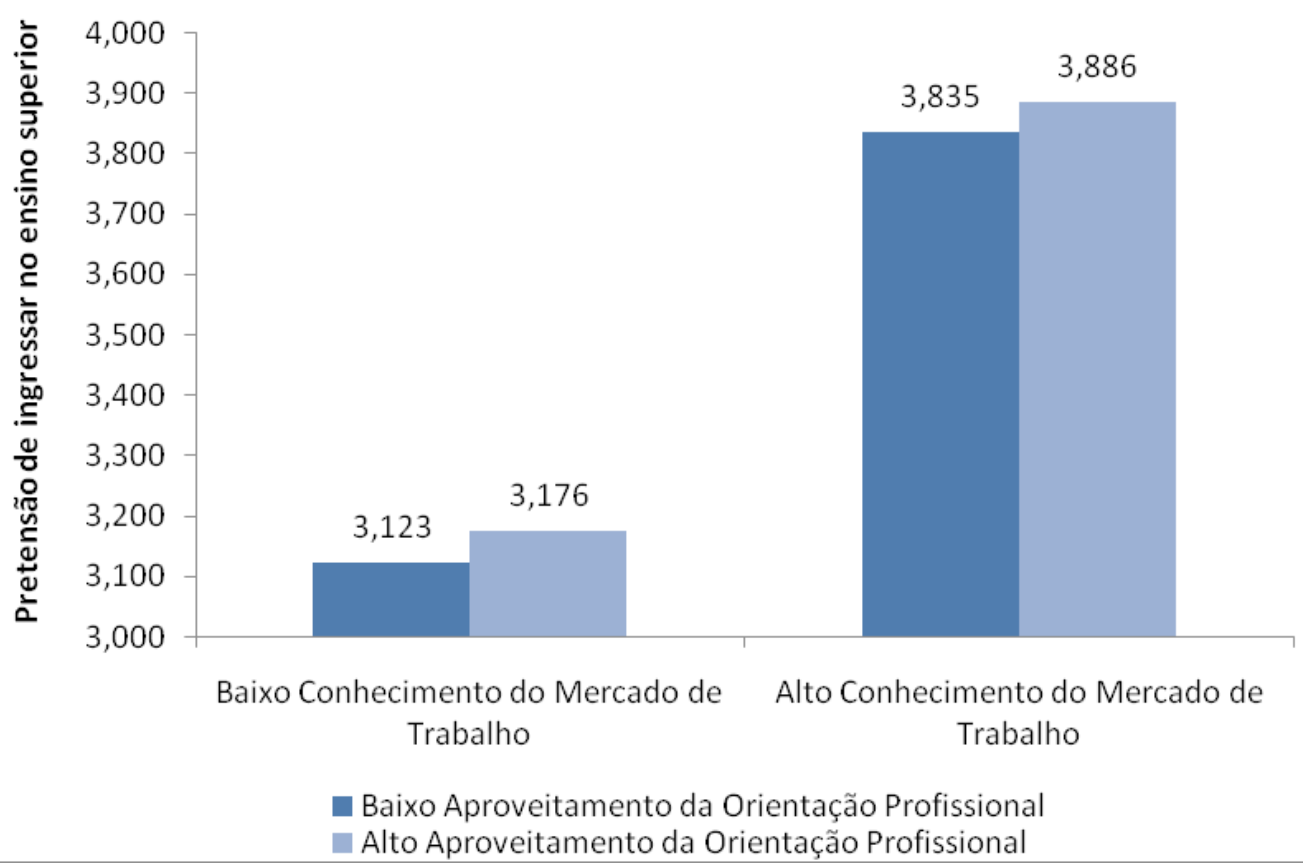

Gráfico 2 - Efeito moderador do Indicador Social do Município Periférico

Fonte: Pesquisa de campo realizada pelos autores em 2013

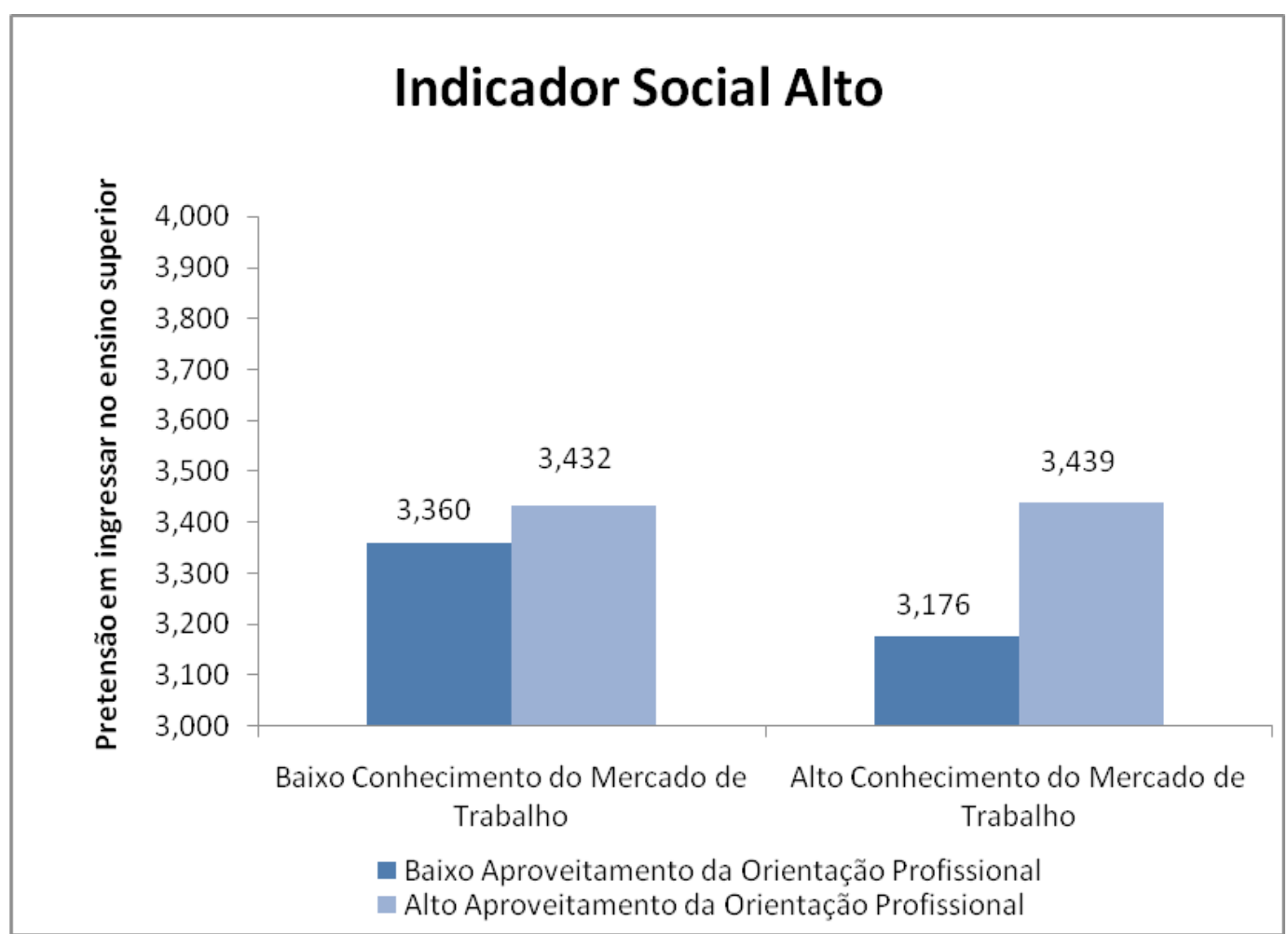

Gráfico 3 - Efeito moderador do Indicador Social do Município Central

Fonte: Pesquisa de campo realizada pelos autores em 2013

Geografia, Ensino \& Pesquisa, Vol. 21 (2017), n.3, p. 37-49

ISSN: 2236-4994 DOI: 10.5902/2236499426329 
aproveitamento do projeto de orientação profissional, sua pretensão de ingressar no Ensino Superior foi à menor dentre todas as combinaçóes. Também nota-se, comparando os gráficos 2 e 3 que os efeitos dos projetos de orientação profissional têm melhor resultado em municípios periféricos do que em municípios centrais. Esse resultado vai ao encontro de nossa argumentação em municípios com melhores indicadores sociais, os jovens possuem mais informaçóes e, consequentemente, o processo de tomada de decisão para ingressar no Ensino Superior é realizado com mais facilidade.

\section{Consideraçóes finais}

Esta pesquisa contribui para o campo do conhecimento da Orientação Profissional por apresentar uma perspectiva interdisciplinar, levando em consideração a realidade econômica e social do espaço em que o jovem reside e o papel dos projetos de orientaçáo profissional como fatores de influência na escolha profissional.

Dentre as conclusôes, em primeiro lugar, esta pesquisa demonstrou que os jovens que possuem informaçōes sobre o mercado de trabalho apresentam melhores condiçóes para a tomada de decisão para ingressar no Ensino Superior. Nas perspectivas teóricas contemporâneas sobre orientação profissional, como a abordagem sócio-histórica de Bock (2002), os autores argumentam que fatores relacionados ao ambiente do indivíduo, como o meio familiar, convívio social e a escola, precisam ser considerados como potenciais influenciadores no processo de decisão do jovem.

Constatou-se que a preocupação não estava assentada na origem da informação que influencia o jovem, mas se essa informação realmente tem um impacto em sua escolha, e foi possível demonstrar que quanto maior é o nível de conhecimento do mercado de trabalho, mais os jovens demonstram pretensão para ingressar no Ensino Superior.

Em segundo lugar, este estudo demonstra que os jovens que participam dos projetos de orientação profissional apresentam mais facilidade no processo de escolha para ingressar no Ensino Superior. Portanto, os projetos de orientação profissional que visam a uma discussão sobre os mecanismos de ingresso para o Ensino Superior, demandas do mercado de trabalho e açóes de autoconhecimento, podem contribuir para a segurança e solidez dos jovens quanto às suas pretensóes futuras.

Em terceiro lugar, foram verificadas como as condiçôes sociais dos municípios em que os jovens residem, vão influenciar nas suas decisôes futuras. A preocupação norteadora do estudo é que os jovens que residem em municípios periféricos podem não construir perspectivas em relação ao futuro profissional e, portanto, estarão sujeitos, passivamente, às únicas ocupaçōes disponíveis, em geral, longe da rota do Ensino Superior, contribuindo para o quadro de esvaziamento populacional, subordinação territorial, dependência econômica e indicadores sociais críticos dos municípios em que residem.

Os resultados demonstram que os jovens residentes em municípios com indicadores sociais baixos e que não tiveram aproveitamento no projeto de orientação profissional, não apresentam como pretensão o ingresso em cursos de Ensino Superior. Dessa forma, constata-se a importância que os projetos de orientação profissional apresentam para os jovens de municípios periféricos, demandando dos agentes públicos uma promoção e investimento em programas contínuos de orientação profissional.

Assim, mediante os fatos abordados, tem-se uma implicaçáo teórica importante para o campo da literatura de Orientação Profissional que diz respeito aos indicadores sociais como uma variável que tem poder de influência na escolha profissional dos jovens. Assim, as futuras pesquisas podem mensurar seus efeitos em outros contextos com diferentes públicos, como a satisfação de egressos com sua profissão e os indicadores de produtividade local, recolocação de profissionais e indicadores de emprego, etc.

Dentre as limitaçóes, destaca-se que esta pesquisa foi realizada com uma perspectiva transversal de recorte temporal, mas futuras pesquisas podem adotar uma perspectiva longitudinal, em que a pretensão dos jovens seja mensurada antes e depois do projeto de orientaçấo profissional. $\mathrm{O}$ mesmo também pode ser feito com o nível de informaçáo que o jovem possui sobre o mercado de trabalho e cursos superiores, podendo consolidar o conhecimento sobre o efeito positivo dos projetos de orientação profissional.

Além disso, outras variáveis do contexto social dos jovens poderiam ser utilizadas na análise. Ribeiro (2003), por exemplo, utiliza em sua análise dados como: a profissão dos pais dos jovens, renda familiar, se os pais ou integrantes do meio social dos jovens possuem curso superior, etc.

Outra limitação deste estudo é considerar como preponderante para os municípios periféricos que os jovens ingressem no Ensino Superior, como forma de se desenvolverem e, consequentemente, o crescimento do próprio município. A esse respeito, Ribeiro (2003) (Continua...) 
realiza uma discussão sobre orientação profissional para jovens de escolas públicas de periferias e argumenta que a Orientação Profissional deve englobar as possibilidades do mundo do trabalho em consonância com cada grupo de orientandos, não se limitando às informaçôes das profissóes de nível superior que impóem aos jovens um modelo único de ascensão socioprofissional.

Nesse sentido, a discussão proposta por Ribeiro (2003) propóe uma mudança de paradigma da Orientação Profissional, na qual os orientadores promovam caminhos para os jovens de acordo com sua realidade socioespacial que pode não ser o Ensino Superior, mas uma inserção rápida no mercado de acordo com a história de seu grupo social. Por exemplo, encaminhar os jovens para cursos técnicos e próximos de sua realidade, já que muitos não terão acesso ao Ensino Superior, dada as deficiências dos municípios periféricos.

Dessa forma, pode-se inferir que a melhor alternativa para os municípios periféricos pode não ser o ingresso de seus jovens no Ensino Superior, já que isso significaria a saída do jovem de seu município de origem para um município que ofereça melhores oportunidades para si. Além do mais, futuramente, quando o jovem for profissional, as melhores oportunidades de ingresso no mercado de trabalho também estarão nos municípios centrais, e não nos periféricos.

Assim, futuras pesquisas sobre orientação profissional e municípios periféricos, sustentadas na teoria sobre Desenvolvimento Local Endógeno (BARQUERO, 2002; COSTA e ROCHA, 2013; FERREIRA, LEOPOLDI e AMARAL, 2014), podem investigar se as perspectivas dos jovens em relação ao seu futuro profissional são incongruentes com o município em que eles residem, e se essa possível incongruência tem impacto direto no desenvolvimento econômico local.

\section{Referências}

BARON, R. M.; KENNY, D. A. The moderator-mediator variable distinction in social psychological research: conceptual, strategic, and statistical considerations. Journal of Personalityand Social Psychology, v. 51(6), p. 1173-1182, 1986. Disponível em: http://citeseerx.ist.psu.edu/viewdoc/ summary?doi=10.1.1.169.4836. Acesso em: 15 mar. 2016.

BARQUERO, A.V. Desenvolvimento endógeno em tempos de globalização. Porto Alegre: Fundação de Economia e Estatística, 2002.

BOCK, S. D. Orientação profissional: A abordagem sócio-histórica. São Paulo: Cortez, 2002.

CASTIONE, R. Planos, projetos e programas de educação profissional: Agora é a vez do Pronatec. Sociais e Humanas. v. 26, n. 1, p.25-42 jan./abr. 2013. Disponível em: https:// periodicos.ufsm.br/sociaisehumanas/article/view/ $\frac{5921 /}{1}$ pdf. Acesso em: 25 mar. 2016.

COSTA, F. R.; ROCHA, M. M. Estudo sobre os municípios periféricos na Mesorregião Centro Ocidental Paranaense. Geografia (Londrina). v. 18, n. 2, p.109-127, 2009. Disponível em: http://www.uel.br/revistas/uel/index. php/ geografia/article/view/2482/3301. Acesso em: 30 mar. 2016.

COSTA, F. R.; ROCHA, M. M. Desenvolvimento local em municípios periféricos. In: BOVO, M. C.; TOWS, R. L.; COSTA, F. R. (orgs). Estudos urbanos em perspectivas: reflexóes, escalas e desafios. Campo Mourão: Editora da Fecilcam, 2013. p. 49-68.

DÁTILO, G. M. P. A.; LIMA, V. G. Orientação profissional - universidade ajuda os jovens a encontrar caminhos profissionais: relato de intervenção. Revista do Laboratório de Estudos da Violência (UNEŞP/Marília). V. 7 n.7, p. $72-$ 83 jun. 2011. Disponível em:

http://www.levs.marilia.unesp.br/revistalevs/edicao7/

autores/RelatoPesquisa1-OrientacaoProfissional.pdf. Acesso em: 11 mar. 2016.

ENDLICH, A. M. O papel das pequenas cidades na rede urbana do Noroeste do Paraná. In: BOVO, M. C.; TOWS, R. L.; COSTA, F. R. (orgs). Estudos urbanos em perspectivas: Reflexóes, Escalas e Desafios. Campo Mourão: Editora da Fecilcam, 2013. p. 27-35.

FERREIRA, A.; LEOPOLDI, M. A.; AMARAL, M. G. Poder público local, universidades e desenvolvimento regional: uma análise da Região do Médio Paraíba Fluminense. Revista Brasileira de Gestão e Desenvolvimento Regional. v. 10, n. 1, p. 305-359, jan./abr. 2014. Disponível em: http://www.rbgdr.net/revista/index.php/rbgdr/article/ view/1222/371. Acesso jun. 2016.

FERRETTI, C. J. Opção Trabalho: trajetórias ocupacionais de trabalhadores das classes subalternas. São Paulo: Cortez, 1988.

FRESCA, T. M. O papel das pequenas cidades na Rede Urbana Paranaense. In: BOVO, M. C.; TOWS, R. L.; COSTA, F. R. (orgs). Estudos urbanos em perspectivas: reflexóes, Escalas e Desafios. Campo Mourão: Editora da Fecilcam, 2013. p. 15-26.

HAIR, J. F. JR.; BLACK, W. C.; BABIN, B. J.; ANDERSON, R. E.; TATHAM, R. L. Análise multivariada de dados. Porto Alegre: Bookman, 2009.

INSTITUTO BRASILEIRO DE GEOGRAFIA E ESTÁTISFICA - IBGE. Censo Demográfico 2010. Rio de Janeiro. IBGE, 2010. 
INSTITUTO PARANAENSE DE DESENVOLVIMENTO ECOMÔMICO E SOCIAL - IPARDES. Municípios do Paraná, Curitiba. IPARDES, 2013.

KUBRUSLY, L. S. Um procedimento para calcular índices a partir de uma base de dados multivariados. Pesquisa Operacional. v. 21, n. 1, p. 107-117, jun. 2001. Disponível em: http://www.scielo.br/pdf/pope/v21n1/a07v21n1.pdf. Acesso em jul. 2016.

LASSANCE, M. C.; SPARTA, M. A orientação profissional e as transformaçóes no mundo do trabalho. Revista Brasileira de Orientaçăo Profissional, v. 4 n. (1/2), p. 13-19, 2003. Disponível em: http://pepsic.bvsalud.org/pdf/rbop/ v4n1-2/v4n1-2a03.pdf. Acesso em: jun. 2016.

LIMA, M. T. Orientação Profissional: princípios teóricos, práticas e textos para psicólogos e educadores. São Paulo: Vetor, 2007.

MARÔCO, J. Análise de equações estruturais: fundamentos teóricos, software \& aplicaçóes. Pêro Pinheiro: Repor Number, 2010

RIBEIRO, M. A. Demandas em Orientação Profissional: Um Estudo Exploratório em Escolas Públicas. Revista Brasileira de Orientação Profissional, n. 4 (1/2), p. 141-151, 2003. Disponível em: http://pepsic.bvsalud.org/pdf/rbop/ v4n1-2/v4n1-2a12.pdf. Acesso jul. 2016.

SILVA, F. F. Construção de projetos profissionais e redução de vulnerabilidade social: subsídios para políticas públicas de orientação profissional no Ensino Médio. 2010. 237p. Tese (Doutorado em Psicologia) - Instituto de Psicologia da Universidade de São Paulo, 2010.

TEIXEIRA, M. A. P.; LASSANCE, M. C. P.; SILVA, B. M. B; BARDAGI, M. P. Produção científica em orientação profissional: uma análise da Revista Brasileira de Orientação Profissional. Revista Brasileira de Orientação Profissional, v. 8, n. 2, p. 25-40, 2007. Disponível em: http://pepsic.bvsalud.org/pdf/rbop/v8n2/v8n2a04.pdf. Acesso em jun. 2016.

TETU, V.; DOMINGUES, A. S.; CHIOCHETTA, L.; VELOSO, M. M. O trabalho de orientação profissional com um grupo de alunos de $3^{\circ}$ ano do Ensino Médio. In: X Congresso Nacional de Educação - Educere, Curitiba, 7 nov. 2011. Anais... Pontifícia Universidade Católica do Paraná, 2011. Disponível em http://educere.bruc.com.br/ CD2011/pdf/5468 2975.pdf, acesso em 25 mai. 2016.

VASCONCELOS, Z. B. Orientação Profissional: breves consideraçóes teóricas. In: VACON̉CELOS, Z. B.; OLIVEIRA, I. D. Orientação Profissional: alguns aspectos teóricos, técnicos e práticos. São Paulo: Vetor, 2004. p. 23-34.

WEST, S. G.; AIKEN, L. S.; KRULL, J. L. Experimental personality designs: analyzing categorical by continuous variable interactions. Journal of Personality, v.1 ou n. 64, p.
1-48, 1996. Disponível em: https://pdfs.semanticscholar. org/346e/6803d8adff413a9def0768637db533fe71b1.pdf. Acesso em jun. 2016.

\section{Correspondência do autor:}

\author{
Marcos Clair Bovo \\ mcbovo69@gmail.com; \\ Fabiane Freire França, \\ prof.fabianefreire@gmail.com; \\ Solange A. Loch, \\ solangeloch@yahoo.com.br \\ Juliano Domingues da Silva \\ ;juliannodomingues@yahoo.com.br
}

ARTIGO RECEBIDO EM: 24/03/2017

REVISADO PELO AUTOR EM: 23/09/2017

ACEITO PARA PUBLICAÇÁO EM: 123/09/2017 